\title{
Learning and Memory Effects of Neonatal Methamphetamine Exposure in Sprague-Dawley Rats: Test of the Role of Dopamine Receptors D1 in Mediating the Long-Term Effects
}

\author{
Sarah A. Jablonski Michael T. Williams Charles V. Vorhees \\ Department of Pediatrics, University of Cincinnati College of Medicine, and Division of Neurology, \\ Cincinnati Children's Research Foundation, Cincinnati, OH, USA
}

\section{Keywords \\ Methamphetamine - Development - Dopamine receptors \\ D1 antagonist · Spatial learning · Egocentric learning · \\ Passive avoidance $\cdot$ Locomotor activity $\cdot$ Rat $\cdot$ SCH 23390}

\begin{abstract}
Methamphetamine (MA) abuse is a worldwide issue that produces health and cognitive effects in the user. MA is abused by some women who then become pregnant and expose their developing child to the drug. Preclinical rodent models demonstrate cognitive deficits following developmental MA exposure, an effect observed in children exposed to MA in utero. To determine if the dopamine receptor D1 (DRD1) is involved in the learning and memory deficits following MA exposure, male Sprague-Dawley rats were treated 4 times daily at $2 \mathrm{~h}$ intervals with 0 (saline) or $10 \mathrm{mg} / \mathrm{kg}$ of MA from postnatal day (P)6-15, $30 \mathrm{~min}$ after $0.5,1.0$, or $2.0 \mathrm{mg} / \mathrm{kg}$ $\mathrm{SCH} 23390$. Cincinnati water maze testing began on P30, and the high dose of $\mathrm{SCH} 23390$ blocked the learning deficits induced by MA with no effect from the lower doses. Morris water maze (MWM) learning deficits following MA were not protected by SCH23390, although there was a non-dose dependent effect in the acquisition phase. Locomotor deficits induced by MA were reversed by all doses of $\mathrm{SCH} 23390$.
\end{abstract}

There were no effects of MA on criterion to trial passive avoidance. Taken together, these data show that behaviors that are dependent on the striatum are better protected with the DRD1 antagonist during MA treatment than the hippocampally mediated spatial learning in the MWM. This suggests that multiple mechanisms exist for the deficits induced by neonatal MA administration.

(c) 2019 S. Karger AG, Basel

\section{Introduction}

Methamphetamine (MA) use among pregnant women continues despite mounting evidence of adverse effects on their children. MA abuse is greater among women 18 24 years of age compared with men (8.9 vs. 3.7\%) [1]. In 2006 , admissions to drug treatment programs receiving federal support indicated that 1 out of 4 pregnant enrollees identified MA as their primary drug of abuse compared with $12 \%$ for nonpregnant women and $7 \%$ for men [2]. In a cohort of pregnant primary MA users, $84 \%$ used during the first trimester, $56 \%$ during the second trimes-

ORCID: M.T.W. 0000-0001-9841-9683, C.V.V. 0000-0003-3558-8812.

\section{KARGER}

(c) 2019 S. Karger AG, Basel

E-Mail karger@karger.com

www.karger.com/dne
Charles V. Vorhees, PhD

Department of Pediatrics, University of Cincinnati College of Medicine Division of Neurology (MLC 7044), Cincinnati Children's Research Foundation 3333 Burnet Ave., Cincinnati, OH 45229-3039 (USA)

E-Mail charles.vorhees@cchmc.org 
ter, and $42 \%$ during all 3 trimesters [3]. Late pregnancy MA users are of interest because brain regions most important for higher cognitive function, including learning and memory, develop primarily during the third trimester [4-8]. MA readily crosses the placenta [9]. In case control studies, MA-exposed children show impaired spatial navigation [10], impaired executive function, disinhibition, and attention deficits [11-17].

Using a late pregnancy exposure model in rats $[18,19]$, we and others find MA-induced spatial learning and memory impairments in the Morris water maze (MWM) [20-34]. Developmentally, exposure to MA on postnatal day (P)6-15 is an especially susceptible period to cause cognitive deficits $[22,25,30,35]$, and this is a stage when brain structures mediating higher cognitive abilities are rapidly developing. More specifically, this period of exposure to MA results in egocentric navigation deficits as assessed in the Cincinnati water maze (CWM) [22, 25]. These effects are greater than those seen after P11-20 MA exposure (Vorhees et al. [36] 2009a and unpublished observation). The CWM is a multiple T-maze, and testing in the dark requires that rats use internal and movement cues to find and remember the correct path to the goal. Learning in this maze is dependent on striatal dopamine [37-39].

We showed that developmental exposure to MA alters locomotor activity after drug challenge with the dopamine receptor D1 (DRD1) agonist (SKF-82958) as adults. MA-exposed offspring exhibited exaggerated hyperactivity compared with saline controls receiving the same dose of SKF-82958 [40]. We also showed that developmental MA exposure results in reductions in PKA activity, one of many postsynaptic downstream effectors of DRD1 activation [34]. These observations may appear opposite; however, the SKF-82958 effects are selective for DRD1, whereas the PKA differences are from homogenized striatal tissue and, hence are nonselective. No data exist concerning PKA changes only in DRD1 striatal neurons. Therefore, we based our hypothesis on our locomotor activity data using SKF-82958, blockade of adult rat neurotoxicity by SCH23390 administered systemically or in striatum [41-44], and unpublished data in adult rats that blockade of DRD1 in the striatum prior to neurotoxic MA attenuates behavioral deficits. In that experiment we infused the DRD1 antagonist SCH23390 into the striatum prior to the administration of MA and found attenuated egocentric learning in the CWM [45]. Therefore, we selected SCH 23390 for the present experiment and hypothesized that it would attenuate developmental MA-induced cognitive deficits.

\section{Materials and Methods}

\section{Subjects and Dosing}

Rats were treated in accordance with protocols approved by the Cincinnati Children's Research Foundation Institutional Animal Care and Use Committee. Rats were maintained in an AAALAC International-accredited vivarium with controlled temperature $\left(19 \pm 1{ }^{\circ} \mathrm{C}\right)$ and humidity $(50 \pm 10 \%)$ and controlled light-dark cycle (14:10 h, lights on at $600 \mathrm{~h})$; all care followed the NIH Guide for the Care and Use of Laboratory Animals in Research. Rats had ad libitum access to NIH-07 rat chow (LabDiet Inc., Richmond, IN, USA) and reverse osmosis filtered, UV sterilized water. Following a minimum of one week of habituation to the vivarium, male and nulliparous female Sprague-Dawley CD IGS rats (strain \#001, Charles River Laboratories, Raleigh, NC, USA) were housed together for breeding on elevated wire floors. Females were placed with the males overnight, and cages were examined daily for a sperm plug. If a sperm plug was found, that day was designated as embryonic day 0 (E0). On E1, gravid females were individually housed in polysulfone cages $(46 \times 24 \times 20 \mathrm{~cm})$ containing woodchip bedding and a stainless steel hut for enrichment [22]. Date of birth was designated P0. On P3, litters were culled to 8 males since prior data demonstrate minor to no differential effects of developmental MA exposure on outcomes for males and females on the tests used here [25]; furthermore, it is not realistic or feasible to do an 8-group within-litter study using both sexes as it would require 16 offspring per litter ( 8 males and 8 females). If a litter was born with fewer than 8 males, 1 or 2 males from a litter that delivered within $24 \mathrm{~h}$ of the target litter was in-fostered so that all litters had 8 male pups. A split litter design was used because it has advantages: (1) we have shown that regardless of litter composition, that is, whether all rats in a litter receive the same dose or they are divided within litters and receive different doses, the effects on behavior are the same [19], (2) split-litter designs provide optimal control for litter effects, including for potential maternal rearing effects, and (3) split litter designs provide control over metagenome and microbiome effects since littermates share the same intestinal flora and fauna [46]

Drugs were obtained from Sigma-Aldrich Co., St. Louis, MO, USA. (R)+SCH23390 was $>98 \%$ pure and administered at doses of $0.5,1.0$, or $2.0 \mathrm{mg} / \mathrm{kg}$ given $30 \mathrm{~min}$ prior to each dose of MA. (+)$\mathrm{MA} \mathrm{HCl}$ was $>95 \%$ pure and the dose was $10 \mathrm{mg} / \mathrm{kg}$ (expressed as the free base) given 4 times/day at $2 \mathrm{~h}$ intervals on P6-15. The vehicle for both drugs was saline $(0.9 \% \mathrm{Sal})$. On P6, a pup in each litter was randomly assigned with the aid of a random number table to one of 8 groups within each litter: (1) Sal/Sal, (2) Sal/MA, (3) $\mathrm{SCH} 0.5 \mathrm{mg} / \mathrm{kg}+\mathrm{Sal}$ (L-SCH-Sal), (4) $\mathrm{SCH} 1.0 \mathrm{mg} / \mathrm{kg}+\mathrm{Sal}$ (M-SCH-Sal), (5) SCH $2.0 \mathrm{mg} / \mathrm{kg}+\mathrm{Sal}(\mathrm{H}-\mathrm{SCH}-\mathrm{Sal})$, and similarly for the MA groups: (6) L-SCH-MA, (7) M-SCH-MA, and (8) H-SCH-MA. SCH23390 and MA were administered subcutaneously in a dosing volume of $3 \mathrm{~mL} / \mathrm{kg}$. The $2 \mathrm{~h}$ treatment intervals consisted of 2 parts. The first injection was SCH23390 or Sal and the second injection 30 min later was Sal or MA. Body weights were recorded at the time of drug administration. Dams were removed from litters on P28, and pups were placed 2 per cage for the remainder of the experiment. Rats were weighed weekly from P21 until testing was completed; the final weight was obtained on P84. About 28 litters were enrolled, and the number of rats used in each test is shown in figure captions. Behavioral testing began on P29. Personnel were blind to treatment group of the pups. As noted, no 


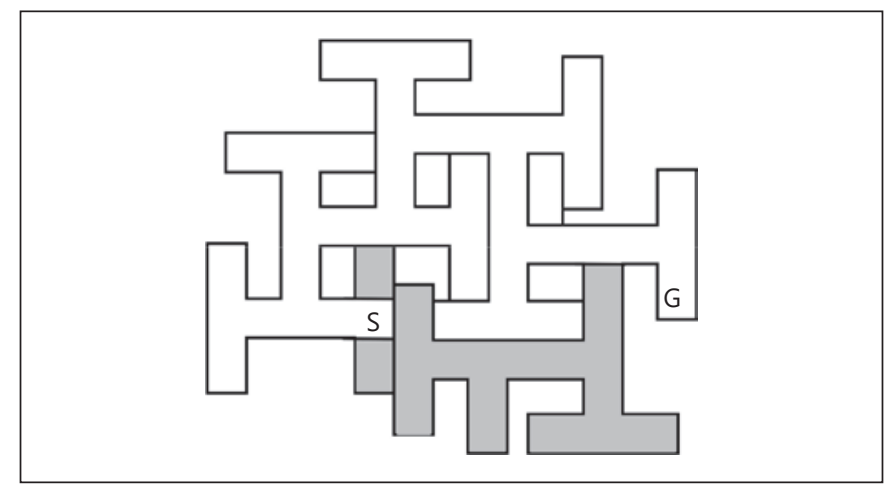

Fig. 1. Simplified CWM: only 6 cul-de-sacs were used with P30 rats. S, start; G, goal.

differential sex effects of MA on learning were found previously $[23,26]$. Testing began on P29 based on previous data that the cognitive effects of P6-15 MA exposure appear this early using the test order below [47].

\section{Straight Channel}

On P29, rats were tested in a $15 \times 50 \times 244 \mathrm{~cm}$ straight swimming channel with a submerged escape platform at the opposite end from the start. Rats received 4 trials. Latency to reach the escape platform was recorded. These trials are essential prior to CWM testing in order to teach rats how to escape. Latencies were analyzed to ensure that all groups had comparable performance and hence comparable motoric ability and motivation to escape.

\section{Cincinnati Water Maze}

Starting on P30, rats were tested in a modified CWM. The full CWM is a 10-unit multiple T-maze [36]. For P30 rats, the number of T-shaped cul-de-sacs was reduced to 6 (Fig. 1) by blocking off part of the maze. Rats were tested under infrared light to prevent access to distal cues. A CCD camera was mounted on the ceiling connected to a video monitor in an adjoining room. Rats were acclimated to the dark for not $<5 \mathrm{~min}$. At the beginning of each trial, rats were placed in the maze and allowed to search for the goal for up to $5 \mathrm{~min}$. Errors (defined as a head and shoulder entry into the stem or arm of a T-shaped cul-de-sac) and latency to escape were recorded. Rats received 2 trials per day for 15 days (P30-44). If a rat found the goal on trial- 1 within 5 min, it was given trial- 2 immediately. If a rat failed to find the goal within $5 \mathrm{~min}$, it was placed in a holding cage with drying material for not $<5$ min before being given trial-2.

\section{Morris Water Maze}

From P50-63, rats were tested in a MWM to assess allocentric, hippocampal dependent learning and memory. The method was that of Vorhees and Williams [48]. The circular tank was constructed of black laminated polyethylene, was $244 \mathrm{~cm}$ in diameter, $51 \mathrm{~cm}$ deep, and filled with water to a depth of $25 \mathrm{~cm}$. Black curtains were mounted on a track on the ceiling but were open on spatial trials to expose distal cues on the walls (geometric shapes and posters). Acquisition (P50-56) consisted of 4 trials per day for 6 days, with a 2 min time limit/trial. Start positions were pseudorandomized and balanced for left and right turns from the start to the goal. If a rat did not find the platform within $2 \mathrm{~min}$, it was placed on it for $15 \mathrm{~s}$. The platform was $10 \mathrm{~cm}$ in diameter and submerged $\sim 2 \mathrm{~cm}$ below the surface and positioned equidistant between the tank wall and the center of the pool in the SW quadrant. Rats were started from one of 4 positions around the perimeter [48]. On the seventh day, a probe trial was given for $30 \mathrm{~s}$ with the platform removed, and the rat was started from a novel position. Dependent variables for learning trials were latency, swim speed, path length, and path efficiency (straight line distance from start to goal $[\mathrm{cm}] \div$ the path taken by the rat, hence unity would be perfect performance). Dependent measures on probe trials were time in the target quadrant, average distance to the former platform site, and swim speed.

A day after completion of acquisition, rats were tested for cognitive flexibility using a reversal procedure (P57-63) by moving the platform to the NE quadrant. They were again tested for 4 trials/day for 6 days with new start positions and with a single probe trial with the platform removed on day- 7 .

\section{Passive Avoidance}

Training. Starting on P65, rats were assessed in passive avoidance (PA) using a Gemini shuttle-box system with 2 chambers each $24 \times 20 \times 20 \mathrm{~cm}$ (SDI, San Diego, CA, USA). The floor consisted of 28 grid bars connected to a scrambled shock generator. A steel gate separated the 2 sides. Eight photodetectors per side recorded movement. A light was mounted on the ceiling of each side. For training, rats were placed in the illuminated side with the gate closed. After $30 \mathrm{~s}$, the gate opened and the rats had up to $180 \mathrm{~s}$ to cross to the dark compartment. When a rat crossed over, the gate closed and following a $5 \mathrm{~s}$ delay, a foot-shock was delivered $(2 \mathrm{~s}, 0.9 \mathrm{~mA}$, through the grid floor). Rats that never crossed over were not tested further. Trials to criterion of remaining on the light side for $180 \mathrm{~s}$ and latency to cross (s) were analyzed as an index of learning.

Retention. Twenty-four hours after training to criterion, rats were placed in the illuminated side again. After a $10 \mathrm{~s}$ delay, the door opened and the rat was given up to $180 \mathrm{~s}$ to cross. If the rat crossed, latency was recorded, but no shock was given. On this trial, latencies were analyzed as an index of memory. Controls reached criterion in 6 days (P65-71) with the retention trial $24 \mathrm{~h}$ later (i.e., P72).

\section{Open-Field Locomotor Activity}

On P75, rats were tested for locomotor activity exploration and habituation in $41 \mathrm{~cm} \times 41 \mathrm{~cm}$ automated photocell activity monitors (PAS, San Diego Instruments, San Diego, CA, USA). Rats were tested for $60 \mathrm{~min}$ for total beam interruptions, consecutive beam interruptions, and center time in 5 min intervals.

\section{Statistical Analysis}

Data were analyzed using mixed linear factorial analysis of variance (ANOVA; Proc Mixed or HP-Mixed, SAS version 9.3, SAS Institute, Cary, NC, USA) with Kenward-Rogers degrees of freedom and autoregressive moving average covariance structure. Models were 1-way ANOVAs in order to compare each treated group with controls. Prior to testing for treatment effects, data from the 4 control groups were compared, that is, Sal-Sal and the $3 \mathrm{SCH}$-Sal groups. They all performed similarly with no significant differences among them or even trends. Therefore, the 4 control groups were merged into one group (Sal-Comb) and tested with the 4 MA-treated groups in $1 \times 5$ ANOVAs. 


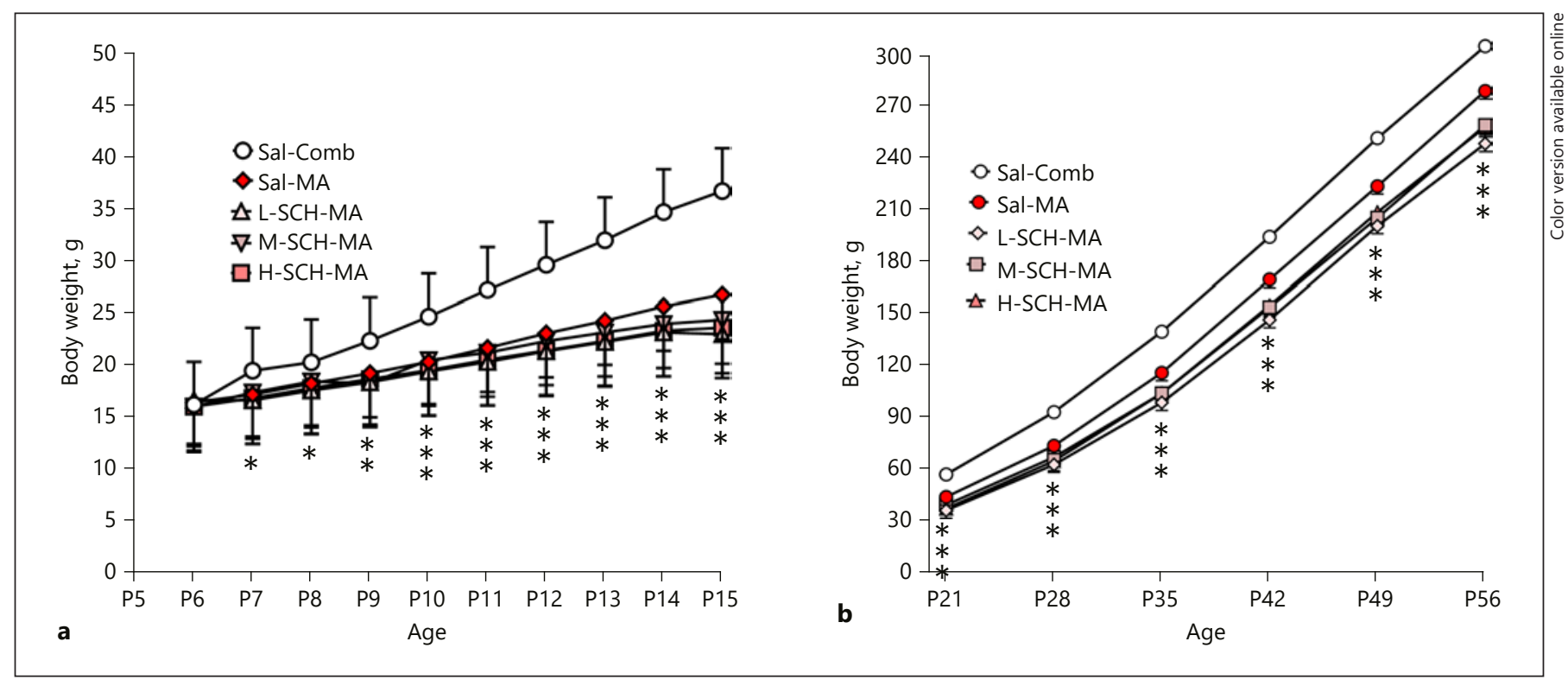

Fig. 2. Body weight. a P6-15 body weight for the MA groups shown individually versus the combined control groups. b P21-56 body weight for the MA and MA+SCH groups vs. the combined control

groups. Data are mean \pm SEM. $n$ : Sal-Comb $=108$, Sal-MA $=24$, L-SCH-MA $=25, \mathrm{M}-\mathrm{SCH}-\mathrm{MA}=17$, and H-SCH-MA $=16 .{ }^{*} p<$ $0.05,{ }^{* *} p<0.01,{ }^{* * *} p<0.001$ or beyond vs. Sal-Comb.

Where there was a repeated measure factor (day, trial, or interval), designs were 1-between, 1-within models. To control for litter effects, litter was a randomized block factor but in no case did it influence the outcome, therefore, it was removed in the final analyses. Significant interactions in the repeated measure ANOVAs were further analyzed using slice-effect ANOVAs. Significance was $p \leq 0.05$. Unidirectional tests were used where previous experiments showed MA-induced deficits, specifically for CWM and MWM. Where prior data were not available, 2-tailed tests of significance were used. Pairwise comparisons used Dunnett's test. $F$ ratios are shown for group and group-related interactions but not for day or interval. Data are presented as least square means \pm SEM.

\section{Results}

\section{General Characteristics}

Body weights during the P6-15 dosing period are shown in Figure 2a. There was a main effect of group $(F[4,182]=45.52, p<0.0001)$ and group $\mathrm{x}$ day interaction $(F[36,1597]=7.9, p<0.0001)$. Slice-effect ANOVAs showed group differences on days P7-15, but not on P6. All groups that received MA gained weight slower than the Sal-Comb group. Body weights for older ages are shown in Figure 2b. Here too, there was a main effect of group $(F[4,192]=37.46, p<0.0001)$ and group $\mathrm{x}$ week interaction $(F[20,808]=3.88, p<0.0001)$. All groups that received MA were significantly lighter than the Sal-Comb group.

Neonatal MA and DRD1 Antagonism

\section{Straight Channel}

There were no effects on straight channel swimming latencies (not shown).

\section{Cincinnati Water Maze}

In order to illustrate how similar the 4 control groups were, the learning curves for these 4 groups for errors are shown in Figure 3a. As can be seen, the performance of the control groups tracked together within a narrow range with slight fluctuations on the first 3 days. From day-4 onward, the data are tightly clustered. The $4 \mathrm{MA}-$ treated groups are plotted separately in Figure $3 \mathrm{~b}$ with the Sal-Sal group for comparison. The rest of the data were analyzed using the Sal-Comb group. There was a main effect of group on errors $(F[4,248]=14.78, p<$ $0.0001)$ with no group $\mathrm{x}$ day interaction. These data are shown Figure 3c averaged over days to show the main effect. A posteriori comparisons revealed that the SalMA, L-SCH-MA, and M-SCH-MA groups had impaired learning, whereas the H-SCH-MA group was not different from the Sal-Comb group, that is, it was protected from MA-induced deficits. For latency there was also a group main effect $(F[4,252]=5.8, p<0.0002)$ with no group $\mathrm{x}$ day interaction. A posteriori group comparisons showed that the L-SCH-MA and M-SCH-MA groups had significantly longer latencies than the SalComb group; however, the Sal-MA and H-SCH-MA 

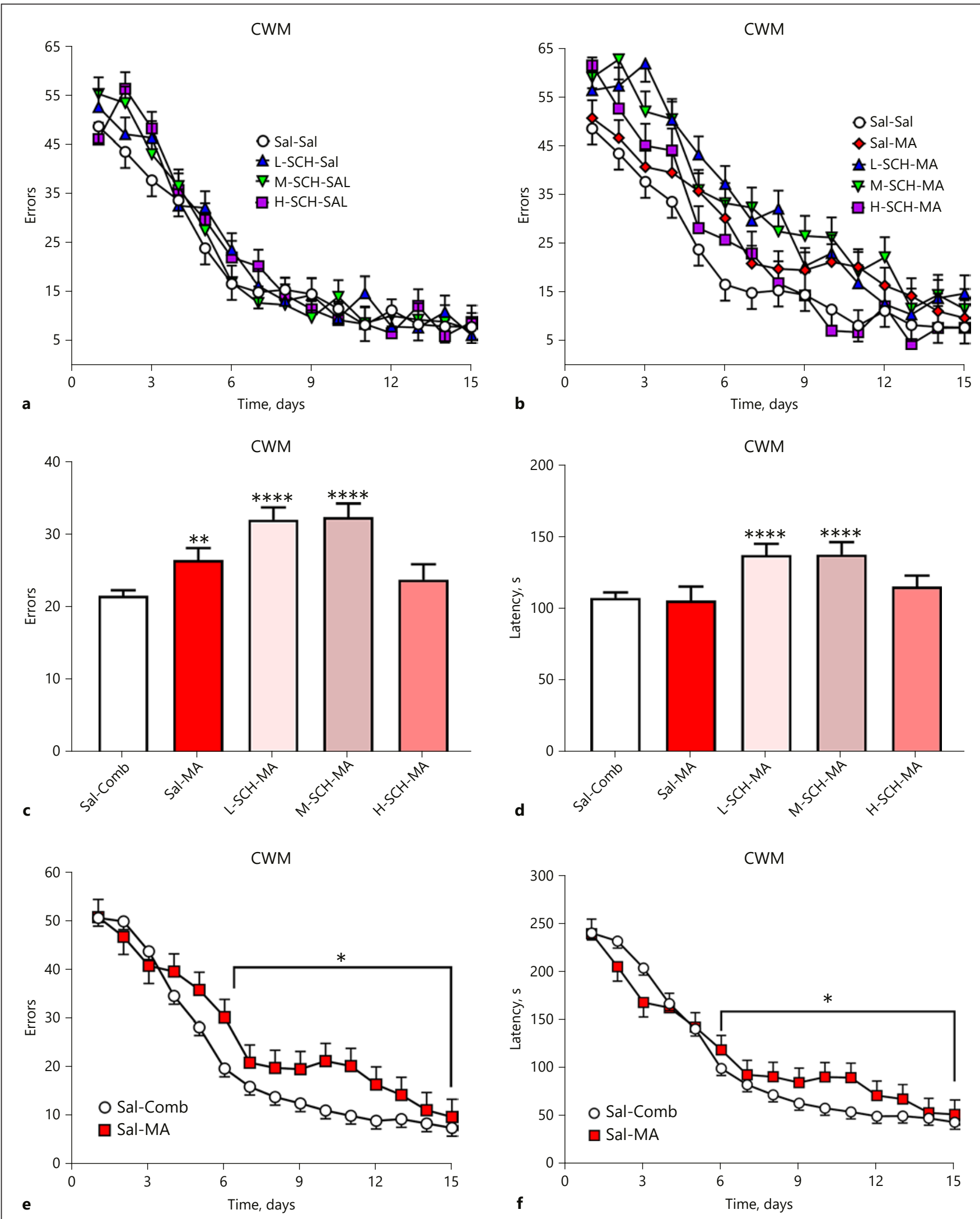

3

(For legend see next page.) 
groups did not differ from Controls. To better understand why the Sal-MA group had increased errors (Fig. 3c) but not increased latency (Fig. 3d), we examined both in greater detail, Figure 3e, f. Both groups started out similarly, but on days 2 and 3, the Sal-MA group for latency, but not for errors, found the goal slightly sooner than Controls. On days 4 and 5, the 2 groups performed almost identically on latency but began to separate on errors. From days 6-15, Controls improved on both measures, whereas the Sal-MA group showed impaired improvement. To test this interpretation, we performed a separate ANOVA on days 5-15. The groups differed significantly on these days $(p<$ 0.04 ) on both measures with the Sal-MA group displaying impaired performance.

\section{Morris Water Maze}

The MWM was conducted in 2 phases: acquisition and reversal; each phase consisted of 4 trials/day for 6 days with a no-platform probe trial on the seventh day. On platform trials, 3 variables were analyzed, latency, distance traveled, and path efficiency. The learning curves for the control groups are shown in Figure 4a. As for the CWM, the MWM acquisition curves for the 4 control groups were nearly identical; there were no significant differences or trends, therefore, these groups were combined. Latency for the experimental groups vs. the Sal-Sal group are shown in Figure $4 \mathrm{~b}$ and in relation to the Sal-Comb group in Figure 4c. Note that the curves for the experimental groups are shifted upward compared with those of the controls. There was a significant main effect of group on acquisition latency $(F[4,176]=7.58, p<0.0001)$ with no group $\mathrm{x}$ day interaction. A posteriori comparisons showed that the SalMA, L-SCH-MA, and H-SCH-MA groups had significantly longer latencies than controls, whereas the $\mathrm{M}$ $\mathrm{SCH}-\mathrm{MA}$ group was not different from Control (Fig. 4d). Latency can potentially be affected by swim speed or other off-target behaviors such as thigmotaxis. To address this, we analyzed path efficiency, that is, the length of a direct path to the goal divided by the path taken by the rat. Analysis of path efficiency on acquisition showed a significant main effect of group

Fig. 3. CWM starting at P30. a Errors by day for the control groups. b Errors by day for the Sal-Sal and the 4 MA-treated groups. c Errors averaged across days for the Sal-Comb and MA groups. d Latency averaged across days for the Sal-Comb and MA groups. e Errors by day for the Sal-Comb and Sal-MA groups. $f$ Latency by

Neonatal MA and DRD1 Antagonism
$(F[4,171]=6.12, p<0.0001)$ with no group $\mathrm{x}$ day interaction. A posteriori comparisons showed the same pattern as for latency, that is, that the Sal-MA, L-SCH-MA and $\mathrm{H}-\mathrm{SCH}-\mathrm{MA}$ groups had reduced efficiency $(\sim 30 \%)$ compared with Controls ( 40\%; Fig. 4e). No differences were found on probe trial measures of memory (not shown).

For reversal with the platform moved to the opposite quadrant, there was a group main effect for path efficiency $(F[4,177]=3.1, p<0.02)$ with no group $\mathrm{x}$ day interactions. A posteriori comparisons showed that all MA-treated groups had reduced path efficiency compared with Controls (Fig. 4f). On reversal, controls showed $\sim 48 \%$ efficiency, whereas the MA-treated groups were $~ 40 \%$ efficient. There were no significant effects on the reversal probe trial (not shown).

\section{Passive Avoidance}

In a previous experiment using the same exposure period and dose of MA, we showed that MA-treated offspring had deficits in CWM, MWM, and radial water maze, but no differences on 1-trial PA [49]. It has been suggested that a trials-to-criterion procedure makes $\mathrm{PA}$ a more sensitive test; therefore, in the present experiment we used this approach. Trials-to-criterion results are shown in Figure 5a, and 24-h retention latencies are shown in Figure 5b. ANOVA on trials-to-criterion showed a significant group effect $(F[4,152]=4.14, p<$ $0.01)$. A posteriori comparisons showed one group difference, that is, the M-SCH-MA group required about one more trial on average to reach criterion than other groups, that is, about 7 versus $\sim 6$ trials for M-SCH-MA vs. Controls. Retention data showed no significant effects (Fig. 5b).

\section{Open-Field Locomotor Activity}

Rats were assessed for exploration and habituation to a novel environment in an automated open field for $60 \mathrm{~min}$. Habituation curves are shown in Figure 6a. ANOVA on the number of photobeam interruptions showed a significant main effect of group $(F[4,328]=4.33, p<0.002)$, whereas the group $\mathrm{x}$ interval interaction was not significant $(F[44,1981]=1.29, p<0.1)$. The main effect of group

day for the Sal-Comb and Sal-MA groups. Data are mean \pm SEM. $n:$ Sal-Sal $=28, \mathrm{~L}-\mathrm{SCH}-\mathrm{Sal}=27, \mathrm{M}-\mathrm{SCH}-\mathrm{Sal}=26, \mathrm{H}-\mathrm{SCH}-\mathrm{Sal}=26$, Sal-MA = 23, L-SCH-MA = 22, M-SCH-MA 18, H-SCH-MA = 15, and Sal-Comb $=107$. $^{*} p<0.05$; $^{* *} p<0.01$; $^{* * *} p<0.0001$ versus Sal-Comb. CWM, Cincinnati water maze. 


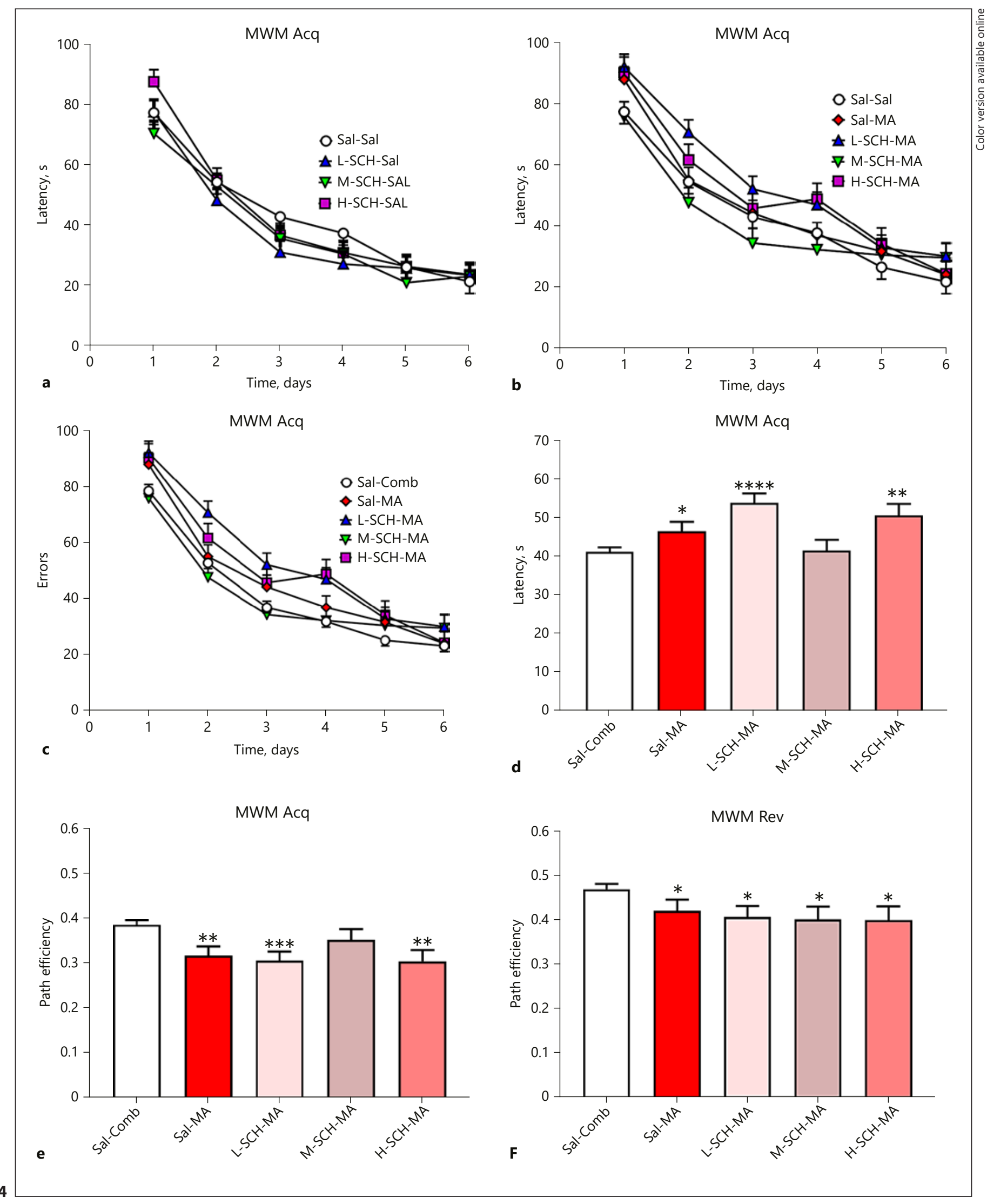

(For legend see next page.) 


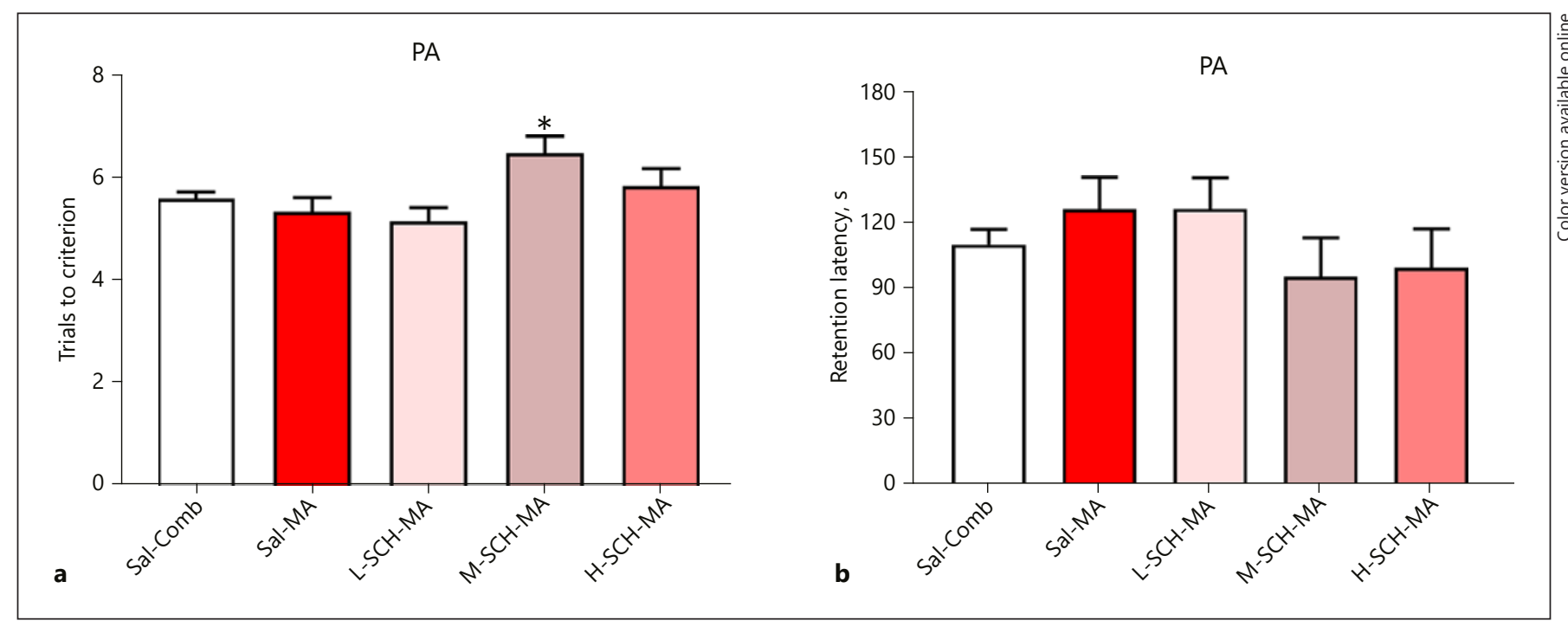

Fig. 5. PA starting at P65. a Trials to criterion of remaining on the lighted side for $180 \mathrm{~s}$. b Crossover latencies on the retention trial given $24 \mathrm{~h}$ after the last training trial. Data are mean \pm SEM. ${ }^{*} p<$
0.05 versus Sal-Comb. $n$ : Sal-Comb $=107$, Sal-MA $=24, \mathrm{~L}-\mathrm{SCH}-$ $\mathrm{MA}=25, \mathrm{M}-\mathrm{SCH}-\mathrm{MA} 18, \mathrm{H}-\mathrm{SCH}-\mathrm{MA}=16 .{ }^{*} p<0.05$ versus SalComb. PA, passive avoidance.

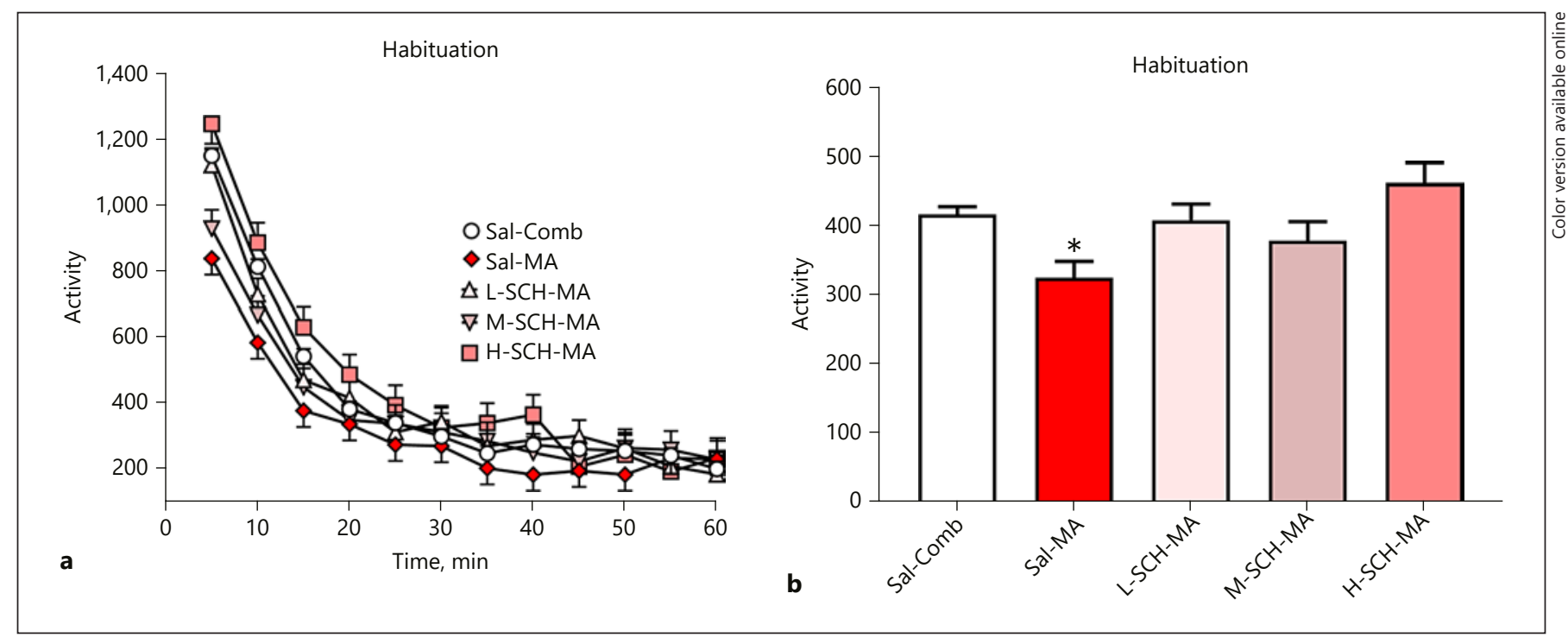

Fig. 6. Open-field locomotor activity at P75. a Activity as reflected by the total number of photobeam interruptions shown in 10-min intervals. b Activity averaged across intervals to show group differences. Data are mean \pm SEM. $n$ : Same as in Figure $5 .{ }^{*} p<0.05$ versus Sal-Comb.

Fig. 4. MWM starting at P50. a Acquisition latency by day for the 4 Sal groups. b Acquisition latency by day for the Sal-Sal and 4 MA-treated groups. c Acquisition latency by day for the Sal-Comb and MA-treated groups. d Acquisition latency averaged across days for the Sal-Comb and MA-treated groups. e Acquisition path efficiency averaged across days for the Sal-Comb and MA-treated groups. $\mathbf{f}$ Reversal path efficiency averaged across days for the SalComb and MA-treated groups. Data are mean \pm SEM. $n$ : same as in Figure $3 .{ }^{*} p<0.05 ;{ }^{* *} p<0.01 ;{ }^{* * *} p<0.001 ;{ }^{* * * *} p<0.0001$ versus Sal-Comb. MWM, Morris water maze. 
averaged across intervals is shown in Figure 6b. A posteriori comparisons showed that only the Sal-MA group differed from Controls. There were no effects on center time.

\section{Discussion}

In this experiment, we tested whether the DRD1 antagonist SCH23390 given prior to MA would protect against P6-15 MA-induced learning, memory, and activity deficits. This was based on previous data that developmentally MA-treated rats show exaggerated hyperactivity in response to a DRD1 agonist [40] and observations that in adult rats pretreatment with SCH23390 directly into the striatum attenuates neurotoxicity (Gross et al. [43]) and CWM egocentric L\&M [45]. In the present study, the low and middle doses of SCH23390 showed no evidence of protection against MA-induced deficits in the CWM, a test of striatal mediated learning and memory [36]. However, the SCH23390 high dose + MA group performed as well as Controls, suggesting that DRD1 is a component of developmental MA-induced egocentric learning deficits. This is consistent with prior data showing that the CWM is a striatal and dopamine-dependent form of learning $[37,39]$.

In the MWM, SCH23390 showed a non-dose-dependent protection against MA-induced spatial learning deficits. This occurred for the middle dose but not for the low or high dose. In addition, this effect was seen only on the acquisition phase and not on reversal. On reversal, all the groups receiving SCH23390 + MA showed impairments with no evidence of antagonist-associated neuroprotection. Overall, the data suggest that DRD1 blockade prior to MA provides modest protective effects on allocentric learning and memory. There were small effects of MA combined with SCH23390 that were slightly different for different measures. For latency, the low- and high-dose SCH-MA groups had longer latencies even than the SalMA group; however, when path efficiency was examined, the low- and high-dose SCH23390 groups performed identically to the Sal-MA group. This suggests that for allocentric navigation SCH23390 may have a modest performance effect, lengthening time to reach the platform without affecting accuracy. If correct, it is possible that this slowing may have offset the beneficial effect of the drug at blocking MA at DRD1 sites. On reversal trials, all groups receiving MA showed impaired path efficiency. Since reversal learning reflects cognitive flexibility, these data suggest that DRD1 antagonism preceding daily P615 MA treatment does not attenuate MA-induced cogni- tive flexibility deficits. However, a more effective DRD1 antagonist might provide greater evidence of neuroprotection than seen with SCH23390 (see below).

Using a multiple-trial PA test, no evidence of MA-induced impairment was seen in the Sal-MA group on either trials-to-criterion or 24-h retention latency. However, on trials-to-criterion, the mid-dose $\mathrm{SCH} 23390+\mathrm{MA}$ group showed a significant but small increase that averaged about one extra trial to reach criterion, that is, $\sim 7$ vs. $\sim 6$ for Controls and the other groups. Overall, the PA data do not support the concept that the insensitivity of this test is attributable to 1-trial versus multiple trial test methods. Rather, the data indicate that PA is an inherently problematic test when used to detect developmental neurotoxicity. This insensitivity was seen in our previous study that tested the effects of pretreatment with alpha-phenyl-N-tertbutyl-nitrone $(\mathrm{PBN})$ where the effects of MA were more pronounced than here [47]. Further, we have replicated the effects of P6-15 MA several times on CWM, MWM, and other behaviors $[25,26]$. However, the fact that PA learning is not impaired after this clearly neurotoxic MA treatment regimen raises questions about the value of $\mathrm{PA}$ for the assessment of learning and memory after developmental exposure even to an established neurotoxin such as MA. These findings may have implications for the use of PA in developmental neurotoxicity safety studies where it is widely used and may be missing neurotoxic effects. If PA cannot provide a point of departure for MA-induced developmental neurotoxicity regardless of the specific test procedure, whereas the CWM, MWM, and radial-water maze can [50], this should raise serious concerns about using PA in developmental neurotoxicity and related safety assessment studies as well as basic research studies. There is no doubt that PA shows effects in acute models for which it was first developed, such as after brain lesions, electroconvulsive shock, or exposure to potent neurotoxins, but it may not be suitable for developmental neurotoxicity hazard identification.

In the automated open field, the Sal-MA group was significantly less active than controls, a finding we documented previously (see review by Jablonski, et al. [19]). In this regard, we note that the $\mathrm{SCH} 23390+$ MA groups all showed activity levels comparable to controls, but not the reduction seen after Sal-MA. This suggests that SCH23390 protected against MA-induced hypoactivity.

We tested rats in this experiment in a modified CWM because they were younger (P30) than in past experiments with developmental MA treatment where we tested the offspring at P50 or older. Therefore, prior to the start of the present experiment, a pilot experiment with untreated 
P30 rats was done. It showed that the full, 10-unit multiple-T, maze was too difficult for P30 rats, that is, none of the P30 rats found the goal. Therefore, we blocked the maze so that there were only 6 Ts and tested additional P30 rats. At this level of complexity, the rats found the goal. Nevertheless, in examining the CWM data from this experiment, and found that even the control groups did not reach full proficiency by test day 15. MA-treated groups did even worse and failed to reach control levels by test day 15. This suggests that more days of testing or using more of the maze, for example, 7 cul-de-sacs rather than 6, might reveal larger group differences. Had this occurred, the beneficial effect of SCH23390 might have been clearer. In any case, greater complexity and more trials would have revealed more fully the extent of the learning deficit caused by MA. In light of these data, future experiments will use 7 cul-de-sacs and more days with P30 rats.

The results support a role for DRD1 in mediating the effects of preweaning MA exposure but there are irregularities in the findings as well. One is that the Sal-MA group did not show effects as large as in previous experiments. It may be that at $\mathrm{P} 30$ rats have not reached their full egocentric cognitive ability, and therefore, the full extent of their deficit had not yet emerged. By simplifying the maze, we may have made it too easy and inadvertently compromised the ability of the test to reveal the full extent of the MA-induced cognitive deficit. Second, since no biomarker exists for the efficacy of SCH23390 at blocking the effects of MA at DRD1 sites, we chose doses and timing based on published data. It is possible, therefore, that we missed the optimal dose and/or timing for administering SCH23390. Furthermore, SCH39166 is a more selective, longer-acting DRD1 antagonist [49] that might be more effective than SCH23390 and should be tried in future experiments. Nevertheless, the data are sufficient to implicate DRD1 in the developmental neurocognitive effects of MA and indicate that further studies of its role would be beneficial. Developmental MA exposure does not induce reductions in dopamine, serotonin, or norepinephrine, nor changes in dopamine transporter or vesicular monoamine transporter-2 protein, hyperthermia, or glial fibrillary acidic protein activation as it does in adult rats [51]. Therefore, the mechanism of action of MA in young rodents remains unknown. There is a report that histamine receptors are involved $[28,50]$ in a mouse model of developmental MA-induced cognitive deficits. MA exposure increased histamine and co-administration of an $\mathrm{H} 3 / \mathrm{H} 4$ antagonist prevented the effects of MA. There is also evidence that reactive oxygen species are involved in the prenatal effects of MA [52] and that these effects can be attenuated by antioxidant drugs. One such drug is the reactive oxygen species trapping agent $\mathrm{PBN}$. This drug blocks MA-induced neurotoxicity in adult rats [53]. We tested this in our neonatal model and found no effects from pretreatment with PBN prior to each MA dose [47]. Therefore, at present, the best leads on how neonatal MA exposure causes egocentric learning deficits and reduced locomotor activity is through a DRD1-mediated mechanism in striatum, and an $\mathrm{H} 3 / 4$ mechanism in the case of allocentric/spatial learning deficits in a MWM $[28,50]$.

In conclusion, the data support that behaviors associated with the striatum, such as egocentric learning and memory and locomotor activity, can be protected from developmental MA-induced deficits by prior blockade of DRD1. Since we saw little improvement in the MWM following DRD1 blockade after MA, this suggests that other mechanisms are driving deficits in spatial learning and memory.

\section{Statement of Ethics}

This research was conducted under an approved Institutional Animal Care and Use Committee of the Cincinnati Children's Research Foundation and complied with AAALAC International standards and the Guide to the Care and Use of Animals in Research of the US. National Institutes of Health and consistent with the ARRIVE (Animal Research: Reporting of in vivo Experiments) guidelines.

\section{Disclosure Statement}

The authors declare no conflicts of interest.

\section{Funding Source}

This research was supported by NIH training grant T32 ES007051 (S.A.J.).

\section{Author Contributions}

The experiment was conceptualized and designed collaboratively by all 3 authors. Dr. Sarah A. Jablonski made the drug solution, bred and treated the rats, and conducted most of the behavioral testing with the assistance of 2 research assistants (Adam Fritz and Chiho Sugimoto, whom we gratefully acknowledge). Dr. Michael T. Williams did the statistical analyses, Dr. Charles V. Vorhees made the figures and wrote the paper, and all authors revised the various draft versions. All authors approved the final version for submission. 


\section{References}

1 SAMHSA. Results from the 2010 National Survey on Drug Use and Health: Summary of National Findings. Rockville, MD, NSDUH Series H-41, HHS Publication. Substance Abuse and Mental Health Services Administration; 2011.

2 Terplan M, Smith EJ, Kozloski MJ, Pollack HA. Methamphetamine use among pregnant women. Obstet Gynecol. 2009 Jun;113(6): 1285-91.

3 Della Grotta S, LaGasse LL, Arria AM, Derauf C, Grant P, Smith LM, et al. Patterns of methamphetamine use during pregnancy: results from the Infant Development, Environment, and Lifestyle (IDEAL) Study. Matern Child Health J. 2010 Jul;14(4):519-27.

4 Clancy B, Darlington RB, Finlay BL. Translating developmental time across mammalian species. Neuroscience. 2001;105(1):7-17.

5 Clancy B, Darlington RB, Finlay BL. The course of human events: predicting the timing of primate development. Dev Sci. 2000;3(1): 57-66.

6 Clancy B, Finlay BL, Darlington RB, Anand KJ. Extrapolating brain development from experimental species to humans. Neurotoxicology. 2007 Sep;28(5):931-7.

7 Clancy B, Kersh B, Hyde J, Darlington RB, Anand KJ, Finlay BL. Web-based method for translating neurodevelopment from laboratory species to humans. Neuroinformatics. 2007;5(1):79-94.

8 Bayer SA, Altman J, Russo RJ, Zhang X. Timetables of neurogenesis in the human brain based on experimentally determined patterns in the rat. Neurotoxicology. 1993;14(1):83144.

9 Rambousek L, Kacer P, Syslova K, Bumba J, Bubenikova-Valesova V, Slamberova R. Sex differences in methamphetamine pharmacokinetics in adult rats and its transfer to pups through the placental membrane and breast milk. Drug Alcohol Depend. 2014 Jun;139: 138-44.

10 Piper BJ, Acevedo SF, Kolchugina GK, Butler RW, Corbett SM, Honeycutt EB, et al. Abnormalities in parentally rated executive function in methamphetamine/polysubstance exposed children. Pharmacol Biochem Behav. 2011 May;98(3):432-9.

11 Abar B, LaGasse LL, Derauf C, Newman E, Shah R, Smith LM, et al. Examining the relationships between prenatal methamphetamine exposure, early adversity, and child neurobehavioral disinhibition. Psychol Addict Behav. 2013 Sep;27(3):662-73.

12 Derauf C, Lester BM, Neyzi N, Kekatpure M, Gracia L, Davis J, et al. Subcortical and cortical structural central nervous system changes and attention processing deficits in preschool-aged children with prenatal methamphetamine and tobacco exposure. Dev Neurosci. 2012;34(4):327-41.

13 Himes SK, LaGasse LL, Derauf C, Newman E, Smith LM, Arria AM, et al. Risk of neurobe- havioral disinhibition in prenatal methamphetamine-exposed young children with positive hair toxicology results. Ther Drug Monit. 2014 Aug;36(4):535-43.

14 Kiblawi ZN, Smith LM, LaGasse LL, Derauf C, Newman E, Shah R, et al. The effect of prenatal methamphetamine exposure on attention as assessed by continuous performance tests: results from the Infant Development, Environment, and Lifestyle study. J Dev Behav Pediatr. 2013 Jan;34(1):31-7.

15 LaGasse LL, Derauf C, Smith LM, Newman E, Shah R, Neal C, et al. Prenatal methamphetamine exposure and childhood behavior problems at 3 and 5 years of age. Pediatrics. 2012 Apr;129(4):681-8.

16 LaGasse LL, Wouldes T, Newman E, Smith LM, Shah RZ, Derauf C, et al. Prenatal methamphetamine exposure and neonatal neurobehavioral outcome in the USA and New Zealand. Neurotoxicol Teratol. 2011 Jan-Feb; 33(1):166-75.

17 Roos A, Kwiatkowski MA, Fouche JP, Narr KL, Thomas KG, Stein DJ, et al. White matter integrity and cognitive performance in children with prenatal methamphetamine exposure. Behav Brain Res. 2015 Feb;279: 62-7.

18 Jablonski SA, Williams MT, Vorhees CV. Mechanisms involved in the neurotoxic and cognitive effects of developmental methamphetamine exposure. Birth Defects Res C Embryo Today. 2016 Jun;108(2):131-41.

19 Jablonski SA, Williams MT, Vorhees CV. Neurobehavioral Effects from Developmental Methamphetamine Exposure. Curr Top Behav Neurosci. 2016;29:183-230.

20 Vorhees CV, Ahrens KG, Acuff-Smith KD, Schilling MA, Fisher JE. Methamphetamine exposure during early postnatal development in rats: I. Acoustic startle augmentation and spatial learning deficits. Psychopharmacology (Berl). 1994 Apr;114(3):392-401.

21 Vorhees CV, Ahrens KG, Acuff-Smith KD, Schilling MA, Fisher JE. Methamphetamine exposure during early postnatal development in rats: II. Hypoactivity and altered responses to pharmacological challenge. Psychopharmacology (Berl). 1994 Apr;114(3):402-8.

22 Vorhees CV, Herring NR, Schaefer TL, Grace CE, Skelton MR, Johnson HL, et al. Effects of neonatal $(+)$-methamphetamine on path integration and spatial learning in rats: effects of dose and rearing conditions. Int J Dev Neurosci. 2008 Oct;26(6):599-610.

23 Vorhees CV, Inman-Wood SL, Morford LL, Broening HW, Fukumura M, Moran MS. Adult learning deficits after neonatal exposure to D-methamphetamine: selective effects on spatial navigation and memory. J Neurosci. 2000 Jun;20(12):4732-9.

24 Vorhees CV, Morford LL, Inman SL, Reed TM, Schilling MA, Cappon GD, et al. Genetic differences in spatial learning between Dark Agouti and Sprague-Dawley strains: possible correlation with the CYP2D2 polymorphism in rats treated neonatally with methamphetamine. Pharmacogenetics. 1999 Apr;9(2): 171-81.

25 Vorhees CV, Skelton MR, Grace CE, Schaefer TL, Graham DL, Braun AA, et al. Effects of (+)-methamphetamine on path integration and spatial learning, but not locomotor activity or acoustic startle, align with the stress hyporesponsive period in rats. Int J Dev Neurosci. 2009 May;27(3):289-98.

26 Vorhees CV, Skelton MR, Williams MT. Agedependent effects of neonatal methamphetamine exposure on spatial learning. Behav Pharmacol. 2007 Sep;18(5-6):549-62.

27 Skelton MR, Williams MT, Schaefer TL, Vorhees CV. Neonatal (+)-methamphetamine increases brain derived neurotrophic factor, but not nerve growth factor, during treatment and results in long-term spatial learning deficits. Psychoneuroendocrinology. 2007 Jul;32(6):734-45.

28 Acevedo SF, de Esch IJ, Raber J. Sex- and histamine-dependent long-term cognitive effects of methamphetamine exposure. Neuropsychopharmacology. 2007 Mar;32(3):66572.

29 Williams MT, Blankenmeyer TL, Schaefer TL, Brown CA, Gudelsky GA, Vorhees CV. Long-term effects of neonatal methamphetamine exposure in rats on spatial learning in the Barnes maze and on cliff avoidance, corticosterone release, and neurotoxicity in adulthood. Brain Res Dev Brain Res. 2003 Dec; 147(1-2):163-75.

30 Williams MT, Moran MS, Vorhees CV. Refining the critical period for methamphetamine-induced spatial deficits in the Morris water maze. Psychopharmacology (Berl). 2003 Jul;168(3):329-38.

31 Williams MT, Moran MS, Vorhees CV. Behavioral and growth effects induced by low dose methamphetamine administration during the neonatal period in rats. Int J Dev Neurosci. 2004 Aug-Oct;22(5-6):273-83.

32 Williams MT, Morford LL, Wood SL, Wallace TL, Fukumura M, Broening HW, et al. Developmental D-methamphetamine treatment selectively induces spatial navigation impairments in reference memory in the Morris water maze while sparing working memory. Synapse. 2003 Jun;48(3):138-48.

33 Williams MT, Vorhees CV, Boon F, Saber AJ, Cain DP. Methamphetamine exposure from postnatal day 11 to 20 causes impairments in both behavioral strategies and spatial learning in adult rats. Brain Res. 2002 Dec;958(2):31221.

34 Crawford CA, Williams MT, Newman ER, McDougall SA, Vorhees CV. Methamphetamine exposure during the preweanling period causes prolonged changes in dorsal striatal protein kinase A activity, dopamine D2like binding sites, and dopamine content. Synapse. 2003 Jun;48(3):131-7. 
35 Vorhees CV, Reed TM, Morford LL, Fukumura M, Wood SL, Brown CA, et al. Periadolescent rats (P41-50) exhibit increased susceptibility to D-methamphetamine-induced long-term spatial and sequential learning deficits compared to juvenile (P21-30 or P31-40) or adult rats (P51-60). Neurotoxicol Teratol. 2005 Jan-Feb;27(1):117-34.

36 Vorhees CV, Williams MT. Cincinnati water maze: A review of the development, methods, and evidence as a test of egocentric learning and memory. Neurotoxicol Teratol. 2016 Sep - Oct;57:1-19.

37 Braun AA, Amos-Kroohs RM, Gutierrez A, Lundgren KH, Seroogy KB, Skelton MR, et al. Dopamine depletion in either the dorsomedial or dorsolateral striatum impairs egocentric Cincinnati water maze performance while sparing allocentric Morris water maze learning. Neurobiol Learn Mem. 2015 Feb;118:55-63.

38 Braun AA, Amos-Kroohs RM, Gutierrez A, Lundgren $\mathrm{KH}$, Seroogy KB, Vorhees CV, et al. 6-Hydroxydopamine-Induced Dopamine Reductions in the Nucleus Accumbens, but not the Medial Prefrontal Cortex, Impair Cincinnati Water Maze Egocentric and Morris Water Maze Allocentric Navigation in Male Sprague-Dawley Rats. Neurotox Res. 2016 Aug;30(2):199-212.

39 Braun AA, Graham DL, Schaefer TL, Vorhees CV, Williams MT. Dorsal striatal dopamine depletion impairs both allocentric and egocentric navigation in rats. Neurobiol Learn Mem. 2012 May;97(4):402-8.

40 Graham DL, Amos-Kroohs RM, Braun AA, Grace CE, Schaefer TL, Skelton MR, et al.
Neonatal +-methamphetamine exposure in rats alters adult locomotor responses to dopamine D1 and D2 agonists and to a glutamate NMDA receptor antagonist, but not to serotonin agonists. Int J Neuropsychopharmacol. 2013 Mar; 16(2):377-91.

41 Sonsalla PK, Gibb JW, Hanson GR. Roles of D1 and D2 dopamine receptor subtypes in mediating the methamphetamine-induced changes in monoamine systems. J Pharmacol Exp Ther. 1986 Sep;238(3):932-7.

42 Broening HW, Morford LL, Vorhees CV. Interactions of dopamine D1 and D2 receptor antagonists with D-methamphetamine-induced hyperthermia and striatal dopamine and serotonin reductions. Synapse. 2005 May; 56(2):84-93.

43 Gross NB, Duncker PC, Marshall JF. Striatal dopamine D1 and D2 receptors: widespread influences on methamphetamine-induced dopamine and serotonin neurotoxicity. Synapse. 2011 Nov;65(11):1144-55.

44 O'Dell SJ, Weihmuller FB, Marshall JF. Methamphetamine-induced dopamine overflow and injury to striatal dopamine terminals: attenuation by dopamine D1 or D2 antagonists. J Neurochem. 1993 May;60(5):1792-9.

45 Gutierrez A, Regan SL, Hoover CS, Williams MT, Vorhees CV. Effects of intrastriatal dopamine D1 or D2 antagonists on methamphetamine-induced egocentric and allocentric learning and memory deficits in SpragueDawley rats. Psychopharmacology (Berl). 2019 Mar 27. DOI: 10.1007/s00213-019-05221-3.

46 Stappenbeck TS, Virgin HW. Accounting for reciprocal host-microbiome interactions in experimental science. Nature. 2016 Jun; 534(7606): 191-9.

47 Jablonski SA, Williams MT, Vorhees CV. Learning and memory effects of neonatal methamphetamine exposure in rats: role of reactive oxygen species and age at assessment. Synapse. 2017 Nov;71(11):1-16.

48 Vorhees CV, Williams MT. Morris water maze: procedures for assessing spatial and related forms of learning and memory. Nat Protoc. 2006;1(2):848-58.

49 Wamsley JK, Hunt ME, McQuade RD, Alburges ME. [3H]SCH39166, a D1 dopamine receptor antagonist: binding characteristics and localization. Exp Neurol. 1991 Feb; 111(2):145-51.

50 Acevedo SF, Pfankuch T, van Meer P, Raber $\mathrm{J}$. Role of histamine in short- and long-term effects of methamphetamine on the developing mouse brain. J Neurochem. 2008 Nov; 107(4):976-86.

51 Yu S, Zhu L, Shen Q, Bai X, Di X. Recent advances in methamphetamine neurotoxicity mechanisms and its molecular pathophysiology. Behav Neurol. 2015;2015:103969.

52 Ramkissoon A, Wells PG. Methamphetamine oxidative stress, neurotoxicity, and functional deficits are modulated by nuclear factor-E2related factor 2. Free Radic Biol Med. 2015 Dec;89:358-68.

53 Cappon GD, Broening HW, Pu C, Morford L, Vorhees CV. alpha-Phenyl-N-tert-butyl nitrone attenuates methamphetamine-induced depletion of striatal dopamine without altering hyperthermia. Synapse. 1996 Oct;24(2): $173-81$. 